\title{
MIR375 Pre-miRNA
}

National Cancer Institute

\section{Source}

National Cancer Institute. MIR375 Pre-miRNA. NCI Thesaurus. Code C101666.

MIR375 pre-miRNA (70 nucleotides) is encoded by the human MIR375 gene. This oligoribonucleotide plays a role in the regulation of gene silencing. 